\title{
Propuesta para la elaboración de un manual para la gestión de los conflictos estudiantiles
}

\author{
Proposal for the development of a manual for the management of student conflicts
}

Recibido 28 noviembre 2012 • Aceptado 23 julio 2013 • Corregido 04 noviembre 2013

\author{
Armando Chacón Mora ${ }^{l}$ \\ Ministerio de Educación Pública, \\ San José, Costa Rica \\ armachacon@gmail.com
}

\begin{abstract}
Resumen.Este artículo se constituye como una propuesta moderna para la gestión de los conflictos estudiantiles, sustentada en la investigación de tipo cualitativo cuyo título fue "Análisis de la percepción de los conflictos estudiantiles de colegios públicos de Costa Rica. En la actualidad son muchas las manifestaciones de conflictos que suceden a diario en las organizaciones educativas nacionales, y sobre las cuales muchos docentes, directores y directoras sienten impotencia no por falta de capacidad sino por la carencia de herramientas para la prevención y atención eficiente de este tipo de situaciones. Desde esta perspectiva es fundamental potenciar las habilidades sociales en los estudiantes elaborando un manual de mediación que no solo sirva como un medio de información, y formación sino que se constituya en una herramienta de mediación para la gestión de los conflictos estudiantiles de las instituciones públicas de Costa Rica. Este manual estará constituido por diversas actividades orientadas a incentivar valores, principios, actitudes necesarias que colaboren con la gestión de los conflictos estudiantiles. Estas habilidades sociales están relacionadas con aspectos tales con: fomento del pensamiento crítico; la comunicación asertiva, el fomento de la resiliencia; los valores que colaboran con la convivencia y la cultura de paz, entre otras.
\end{abstract}

Palabras claves. Administración, educación, Gestión de los conflictos, educación en valores, asertividad, convivencia pacífica.

Abstract. This article is a modern proposal for the management of student conflicts, based on the research of qualitative type whose title was "Analysis of the perception of the student conflicts in public schools in Costa Rica". Today there are many manifestations of conflicts that occur daily in the national educational organizations, and on which many teachers and principals feel impotence

1 Doctor en Ciencias de la Educación de la Universidad Católica de Costa Rica. Magister en Ciencias de la Educación con énfasis en Administración Educativa y en Gestión Jurídica de la Educación de la Universidad de Costa Rica (UCR). Licenciado en Filosofía de la Universidad Católica Madre y Maestra de República Dominicana. Actualmente es director del Liceo Experimental Bilingüe La Trinidad de Moravia, del Ministerio de Educación Pública (MEP). 
not by lack of capacity but by lack of tools for the prevention and efficient attention for this type of situation. From this perspective, it is essential to promote social skills in students preparing a manual of mediation which not only serves as a means of information, and training, but it constitutes a tool for mediation for the management of student conflicts of public institutions in Costa Rica. This manual shall consist of activities aimed to encourage values, principles and attitudes needed to collaborate with the student conflict management. These social skills are related to aspects such as: promotion of critical thinking; assertive communication, the promotion of resilience; the values that collaborate with the coexistence and the culture of peace, among others.

Keywords. Administration, education, conflict management, education in values, assertiveness, peaceful coexistence.

\section{Introducción}

En la actualidad, la gestión administrativa de los conflictos requiere de las instituciones educativas y sus administradores, una serie de competencias relacionadas no solo con la gestión de estos procesos, sino también con la adquisición de estrategias, habilidades y valores concernientes a la prevención e intervención de los diversos conflictos estudiantiles que se suscitan dentro y fuera de las organizaciones educativas. Todo esto implica que, a nivel organizacional, se convierta en imperativo y en una prioridad, la construcción de un manual moderno para la gestión de los conflictos estudiantiles.

Para esto, esfundamental la potenciación delas habilidades sociales en los estudiantesy docentes, por medio de la implementación de un manual de mediación que no sirva como un instrumento de información y que constituya una herramienta de gestión de los conflictos estudiantiles.

Este manual está constituido por diversas actividades orientadas a incentivar valores, principios y actitudes básicas que colaboren con la gestión de los conflictos estudiantiles, a partir de un proceso de toma de conciencia del fenómeno y asumiendo, con responsabilidad, los compromisos que deben adquirirse según el manual. Así mismo, deben considerarse todos aquellos factores configurativos del contexto institucional y social de los adolescentes que ejercen influencia en el comportamiento juvenil, para realizar una intervención efectiva desde diversas áreas: la personal, la social (colegio, familia y sociedad) y la parte trascendente (valores, principios, normas, entre otros).

\section{Objetivo general de la propuesta}

- Elaborar un manual para la prevención e intervención de los conflictos estudiantiles, a partir del fomento de algunas habilidades sociales que colaboren con la construcción y el fortalecimiento de un ambiente relacional positivo en el Liceo de Costa Rica. 


\section{Objetivos específicos}

- Determinar habilidades sociales que coadyuven en la estructuración de un manual para la atención de los conflictos estudiantiles.

- Diseñar una manual para la atención y prevención de los conflictos estudiantiles en las organizaciones educativas.

- Implementar el desarrollo de algunas habilidades sociales por medio de dinámicas grupales que colaboren con la gestión de los conflictos estudiantiles en las organizaciones educativas.

\section{Referente teórico}

\section{Educación}

La educación juega un papel preponderante como instrumento de desarrollo personal y social, pues le permite al ser humano reflexionar acerca de su vida y su contexto. La actividad educativa, en la actualidad, se constituye en una de las principales prioridades a nivel político y económico, debido a que una buena educación promueve el progreso científico-tecnológico, factores indispensables para el desarrollo humano. La búsqueda de este desarrollo demanda que los estados nacionales realicen una inversión grande en el campo educativo, para dar una respuesta coherente ante los diversos desafíos que el contexto demanda. Estos desafíos han sido analizados y determinados por la Organización de las Naciones Unidas para la Educación, la Ciencia y la Cultura (UNESCO), en el Informe La Educación encierra un tesoro, Delors (1996), el cual establece cinco pilares fundamentales que requiere la educación del siglo XXI.

Estos pilares de la educación, a nivel administrativo educativo son fundamentales, sobre todo en lo que compete a la construcción de una propuesta eficiente para la gestión de los conflictos estudiantiles se refiere; de allí, que los cinco pilares propuestos por Delors (1996), hacen referencia a temas tales como: aprender a convivir, aprender a vivir juntos, aprender a conocer, aprender a hacer y aprender a ser. De esta forma, la misma se constituye en una herramienta fundamental para la intervención, mediación y prevención de los conflictos estudiantiles, tal como lo plantea González (2009), quien menciona que en el nivel administrativo deben gestionarse todos aquellos recursos que estén a disposición para el logro de un ambiente escolar pacífico. Por estas razones, el profesional en administración de la educación debe ser un facilitador del cambio, un agente para la transformación institucional que colabore en brindar las herramientas necesarias para enfrentar los diferentes retos que a nivel social, cultural y humano se le presentan. Entre estos retos destacan los conflictos estudiantiles. 


\section{Los conflictos estudiantiles}

El contexto social dentro del cual crecen y se desarrollan los adolescentes, es complejo; éste se constituye en un generador de conflictos. Desde esta perspectiva, la crisis en la cual están insertos todos los países en la actualidad, se ve expresada por medio de la pobreza, el desempleo, la insatisfacción de las necesidades básicas, la condición socioeconómica; todos estos factores que, según Fernández (2008) generan climas conflictivos, violentos. Por ende, las organizaciones educativas se constituyen en receptoras de diferentes tipos de conflictos, ya sea en el nivel endógeno como exógeno. Al respecto, se destaca que:

Se designa como factores endógenos a todos aquellos acontecimientos que a nivel interno institucional, provocan conflictos entre los estudiantes. Entre estos factores de origen endógeno se destacan: la crisis de valores; la falta de docentes que sirvan de referente a los estudiantes y la desvalorización del sentido que tiene la institución como organización educativa, Los conflictos en los centros educativos suelen suceder de diversas maneras, el mismo es un problema multicausal, Estos factores están íntimamente relacionados con el contexto social, familiar se conjugan en conductas antisociales en los centros educativos, por los niños y jóvenes que en ellos estudian y que en muchos casos perciben las normas establecidas en la institución y su misma situación económica. (Chacón, 2011, p. 19)

\section{Gestión de los conflictos estudiantiles}

La administración en el campo educativo juega un papel preponderante, en lo que a gestión se refiere. La gestión administrativa por sí misma, induce a las organizaciones a perfilarse como un conjunto ordenado, jerarquizado, planificado y teleológicamente dirigidas al logro de objetivos, los que a su vez se orientan hacia una administración eficiente, tanto del recurso humano como de los materiales. Desde esta perspectiva, el acto administrativo implica:

Interpretar los objetivos propuestos por la organización y transformarlos en acción organizacional, a través de la planeación, organización, la dirección y el control de todos los esfuerzos realizados en las áreas y en todos los niveles de la organización, con el fin de alcanzar tales objetivos de la manera más adecuada a la situación y garantizar la competitividad en un mundo de negocios muy competitivo y complejo. (Chiavenato, 2006, p. 10)

La administración de la educación se constituye en el eje sobre el cual giran todas y cada una de las diversas actividades, propuestas, iniciativas e innovaciones que surgen en las organizaciones educativas; su principal propósito se enfoca en la búsqueda del mejoramiento continuo y la calidad educativa. Según esto, es muy difícil que, dentro de un entorno educativo conflictivo, se susciten aspectos relativos al mejoramiento continuo y a la calidad que se menciona. Al respecto, Chiavenato (2006) opina que la administración debe sustentarse en una 
planificación, organización, dirección y control de los actos educativos, los cuales emergen a lo interno y externo de la organización educativa; éstos pueden ser medibles y cuantificables para buscar, constantemente, la mejora continua, la optimización de los recursos y los estándares necesarios que garanticen un servicio de calidad.

Es importante en el nivel de la administración de la educación, que los directores posean las competencias necesarias para la gestión de los recursos humanos, materiales y financieros, sobre todo en lo que respecta a la gestión de los conflictos estudiantiles; de esta forma, ejecutar con eficiencia sus funciones y con eficacia los recursos que posee. De acuerdo con lo anterior, el profesional en administración de la educación debe constituirse también en gestor para la solución de conflictos. Para esto, debe poseer una serie de competencias relacionadas con la gestión de los conflictos estudiantiles, con el fin de intervenir cada uno de los diferentes acontecimientos que, a nivel interno y externo, suceden en torno a la organización educativa. Una administración eficiente debe prever todas aquellas situaciones que, de índole conflictiva, podrían suscitarse en la organización; asimismo, fortalecer aquellas que coadyuven al mejoramiento institucional, entre ellas los conflictos estudiantiles.

Por esto, a nivel de gestión, el profesional en administración de la educación debe estar en una incesante exploración de alternativas efectivas para la organización, en lo que a la prevención e intervención de los conflictos se refiere. De allí, la urgente necesidad de que los directores y directoras, lejos de convertirse en meros tramitadores de procedimientos administrativos, se constituyan en gestores, en partícipes, en generadores de alternativas, procesos, manuales, los cuales deben planificarse e intensificarse como un componente esencial del proyecto educativo institucional.

Desde esta perspectiva los conflictos pueden ser confrontados de forma multidisciplinaria; no se trata de un plan remedial de las organizaciones educativas, más bien es un proyecto integral y permanente dentro del cual deben estar involucrados todos y cada de los miembros que pertenecen a la comunidad educativa. Para una eficiente gestión de los conflictos es primordial que el administrador educativo (a), no solo posea un conocimiento básico en relación a la naturaleza de los conflictos estudiantiles, sino también adquirir las competencias necesarias (capacidad de negociación, el arbitraje y la mediación), el abordaje eficaz y constructivo de los mismos. (Chacón, 2011, p.173)

Desde esta visión, todo profesional en administración de la educación ha de implementar un plan de acción para la prevención e intervención de los diferentes conflictos que se presenten en la institución, como parte del proyecto organizacional y de su plan operativo institucional. Asimismo, debe tomar en cuenta que sus colabores inmediatos requieren también del conocimiento y las competencias básicas para la gestión de los conflictos. Para esto, las capacitaciones, el fomento de un clima organizacional sano, la mediación de los conflictos, el 
fomento de las habilidades sociales, entre otros, se constituyen en factores esenciales que se deben tomar en consideración para así, cumplir con sus metas organizativas en estos aspectos. No obstante, cabe resaltar que esto compete a la gestión de los conflictos estudiantiles y es fundamental aclarar, que no existe un estilo único de gestión, sino múltiples estilos; cada uno de ellos está íntimamente relacionado con el estilo de gestión administrativa que el director ejecuta.

Según esto, el proyecto educativo institucional se convierte en el punto de partida para el establecimiento de una cultura para la atención y prevención de los conflictos; su finalidad fundamental es coadyuvar a la comunidad educativa en la toma de conciencia y adquisición de una filosofía en torno al mejoramiento continuo, al trabajo en equipo, a tener claro los objetivos institucionales, su misión, visión y los valores organizacionales; así como todo lo referente a las micropolíticas y macropolíticas que emanan, ya sea a lo interno como a lo externo de la organización educativa, como todas aquellas actividades que fomenten la convivencia entre todos los integrantes de la comunidad educativa, respondiendo con estos a las demandas sociales.

Desde esta perspectiva la institución educativa debe aprender a desarrollar actividades inclinadas a prever los periodos críticos o a dirigir los cambios y a ser flexibles ante los nuevos retos, las nuevas variables y exigencias de la sociedad del conocimiento. (Chacón, 2011, p.174)

Por otra parte, otro factor por considerar en el nivel administrativo de la educación, es la familia, no solo porque se establece como una célula fundamental del núcleo social, sino también porque se constituye en un factor que puede favorecer conductas de índole conflictiva y violenta en los jóvenes, ya que es la principal fuente de modelización de los niños y jóvenes, dentro de ella es donde se asimilan los valores, costumbres y hábitos que van a ser importantes a lo largo de toda su vida. Desde esta representación, la familia puede convertirse también en promotora de disvalores y conductas antisociales, todo lo contrario, a lo anteriormente expuesto.

Debido a todos estos factores, los cuales se convierten en causales de los diferentes tipos de conflictos que a nivel social y educativo presentan los jóvenes, se hace indispensable la construcción e implementación de un manual moderno fundamentado en la educación en valores, el fomento de la solidaridad y la convivencia entre los jóvenes, la adquisición de habilidades tales como la asertividad y la resiliencia, entre otras, que respondan a los desafíos que enfrentan los profesionales en administración de la educación y las organizaciones educativas actuales. 


\section{La educación en valores}

En lo que compete a la prevención de los conflictos, la educación en valores debe ser una alternativa para encontrar soluciones a los problemas que plantean la vida y aprender a solucionar, constructivamente, los conflictos de la vida cotidiana. Asimismo, una adecuada educación en estos aspectos, debe ser modelo en transmisión de valores absolutos que vayan relacionados en torno a un modelo de socialización, el autoconocimiento, la adquisición de virtudes y valores morales, entre otros, que parta de las experiencias y problemas reales que se suscitan en la cotidianeidad.

Esta formación en valores ha de fundamentarse en un ejercicio responsable de la libertad que posee toda persona como un derecho fundamental; de allí, la necesidad de educar en la libertad, vista la misma como la capacidad humana de optar por aquello que le conviene para la preservación de su vida y la de los otros, escogiendo valores que le favorezcan el adecuado y auténtico conocimiento de sí mismo y un auténtico desarrollo personal y comunitario. Por esto, un profesional en administración de la educación debe ser ante todo, un modelo en valores en su vida y en su gestión administrativa. Una educación en valores exige la presencia de directores y educadores coherentes, que fomenten transparencias en sus actos, gestionen el diálogo, la honestidad y la responsabilidad. Entre otros valores que se constituyen en importantes en cualquier contexto educativo, están:

El respeto: aquí entra en juego la buena educación, civismo, respeto a los mayores y la aceptación de las correcciones.

La amistad: saber hacer amigos, al valorar la amistad en su justa medida.

La responsabilidad: sin perfeccionismo, pero que cumpla con los acuerdos, tareas y trabajos proyectados.

La alegría: que vivan con ilusión, aprendan a sorprenderse, a ver lo positivo de las personas y las cosas, con una visión entusiasta, antes que trágica y moralista.

La sinceridad: darle la oportunidad de manifestarse tal cual es sin temor a decir la verdad o preguntar, siendo transparente, sin miedo al juicio categórico, dogmático y moralizante.

La generosidad: se deben fomentar la cultura del dar y la generosidad, la solidaridad como un medio idóneo de ser feliz y hacer felices a otros.

La fortaleza: si tiene confianza en sí mismo, tendrá suficientes fuerzas para poder resistir todo tipo de situaciones y manipulaciones y podrá visualizar su vida con esperanza, gentileza y coraje.

La tolerancia: sin intransigencias, sin autoritarismos, se debe dar ejemplo de tolerancia, de la espera edificante y del perdón. La fidelidad a su moral: Es el núcleo lo que mora dentro de cada uno e implica toda la personalidad. (Tierno, 1994, p. 178) 


\section{Educación en la solidaridad}

En el nivel de la gestión administrativa de la educación, el valor de la solidaridad constituye un factor esencial en la construcción y consolidación de la convivencia institucional y al mismo tiempo, fortalece tanto a lo interno como a lo externo, el ejercicio del bien común, lo que establece un vínculo comunidad-centro educativo basado en una relación de mutua cooperación y diálogo. La crisis de valores y la deshumanización que sufre la sociedad actual, es una razón de más para formar en valores, entre ellos la solidaridad.

Desde el punto de vista de Gómez (2001), la juventud en la actualidad, ha pasado a un primer plano, pues su poder e influencia es mucho mayor que hace unos años; todo esto, auspiciado por la influencia de los medios de comunicación social y las redes sociales. Por esto, los jóvenes constituyen, sin duda, un sector muy influenciado e influyente a nivel social.

Los conflictos estudiantiles se producen a causa del contraste en que viven los adolescentes mientrassueñan,imaginan eintentan ponerleentusiasmoasusactividades.Losjóvenessientenfrustración ante una sociedad adultocéntrica dentro de la cual se idolatra el consumismo, existe desigualdad social, corrupción política y un acusado conservadurismo e hipocresía que, en muchos casos, se convierten en causa eficiente de los conflictos estudiantiles en las organizaciones educativas (Gómez, 2001).

Desde esta perspectiva, es necesario dentro de las organizaciones educativas, gestionar proyectos tendientes al desarrollo en los discentes de la capacidad crítica, para contrarrestar los efectos negativos que el contexto próximo les induce. Para esto, el fomento de la capacidad crítica, producto de un proceso de acompañamiento y orientación, ayudará al educando a despertar sus potencialidades, pasando de ser un receptor pasivo a un preceptor activo, sobre todo crítico.

\section{Educación en la comunicación asertiva}

La comunicación es un instrumento que permite la interacción entre las personas en torno a todos los acontecimientos que suceden a diario y de los cuales existe necesidad de comunicar. Es por medio de la comunicación donde las personas expresan sus necesidades; de allíla necesidad, a nivel educativo, de una gestión de acciones pertinentes a consolidar una formación integral que fortalezca y potencie una comunicación asertiva, como un medio eficaz de comunicación. Entrenarse en las técnicas asertivas provoca en el sujeto un cambio que eleva su autoconcepto, le enseña a no temer enfrentar los conflictos; asimismo, más productivo y útil. Una conducta asertiva incluye, en forma directa, la expresión de los sentimientos, preferencias, necesidades u opiniones, aspectos primordiales en lo que a prevención de los conflictos se refiere. 
Un joven ejercitado en la asertividad, tendrá mucho más oportunidades de ser más disciplinado, no solo en un nivel conductual sino también académico. En la actualidad, las necesidades de los niños y jóvenes se han transformado; los diversos cambios sociales, las formas de convivencia y otros, provocan la búsqueda de estrategias que llenen las expectativas de una sociedad marcada por la violencia social. La gestión administrativa de la educación debe centrarse también, en la apertura de canales de comunicación viables dentro de las organizaciones educativas.

\section{Desarrollo de la resiliencia}

Desde la antigüedad, la humanidad ha sido testigo de su capacidad innata para superar las adversidades. Al respecto, Suárez (1998) menciona que, a lo largo de esta misma historia, han aparecido individuos destacados y con aportes significativos para la humanidad, los cuales debieron enfrentar circunstancias adversas, destacando a Demóstenes, Víctor Frankl, Karol Wojtyła y Rigoberta Menchú.

Pueblos enteros o grupos étnicos han demostrado sorprendentes capacidades para sobreponerse de la pobreza, el aislamiento, catástrofes naturales o generadas por el mismo ser humano. Estos pueblos y personas se caracterizan por haber generado competencias en medio de la adversidad; para buscar una explicación a estas circunstancias se utiliza el término "resiliente", el cual expresa las características antes mencionadas y que, junto con el sustantivo "resiliencia", es adecuado para expresar esa condición (Suárez, 1998).

De acuerdo con esto, la resiliencia es la capacidad humana para hacer frente a las adversidades de la vida y superarlas. La resiliencia es vista como una habilidad para surgir de la adversidad, adaptarse, recuperarse y acceder a una vida significativa y productiva, con el fin de ser transformado por ellas. Gestionar las adversidades significa, para un profesional en administración de la educación, transformar esas fuerzas negativas y factores de riesgo en un complemento enriquecedor que acreciente su aptitud para analizar la realidad y crear acciones eficaces. La resiliencia no es un instrumento clínico, neutro; sino que en la vida real, exige acciones tendientes a la superación de los obstáculos y las presiones a las que está sometida la comunidad educativa (Grotberg citado por Suárez, 1998).

\section{Estructura y descripción del manual para la prevención e intervención de los conflictos estudiantiles}

La confección del manual para la prevención e intervención de los conflictos estudiantiles, permitirá al profesional en administración de la educación, gestionar e intervenir de múltiples maneras, los diferentes tipos de conflictos que se presentan a nivel organizacional dentro de la comunidad educativa. Esta propuesta se sustentará en estrategias que van desde un 
trabajo personal (dinámicas para el conocimiento personal) hasta actividades diversas de tipo colectivas (trabajos en pequeños grupos), las cuales permitirán tomar conciencia de las diferentes situaciones (conflictos) que a menudo se experimentan en el nivel personal y social.

Este manual se dirige a toda la comunidad educativa: padres y madres de familia, docentes, estudiantes y personal administrativo de las organizaciones educativas, tal como se muestra en la figura 1. El mismo, debe ser liderado por la dirección institucional, en quien recae la responsabilidad de implementarlo. Es importante resaltar que el manual no es un producto acabado, siendo el ser humano y la sociedad misma, entidades en constante transformación. Cada uno de los procesos debe adaptarse a las diversas evoluciones sociales.

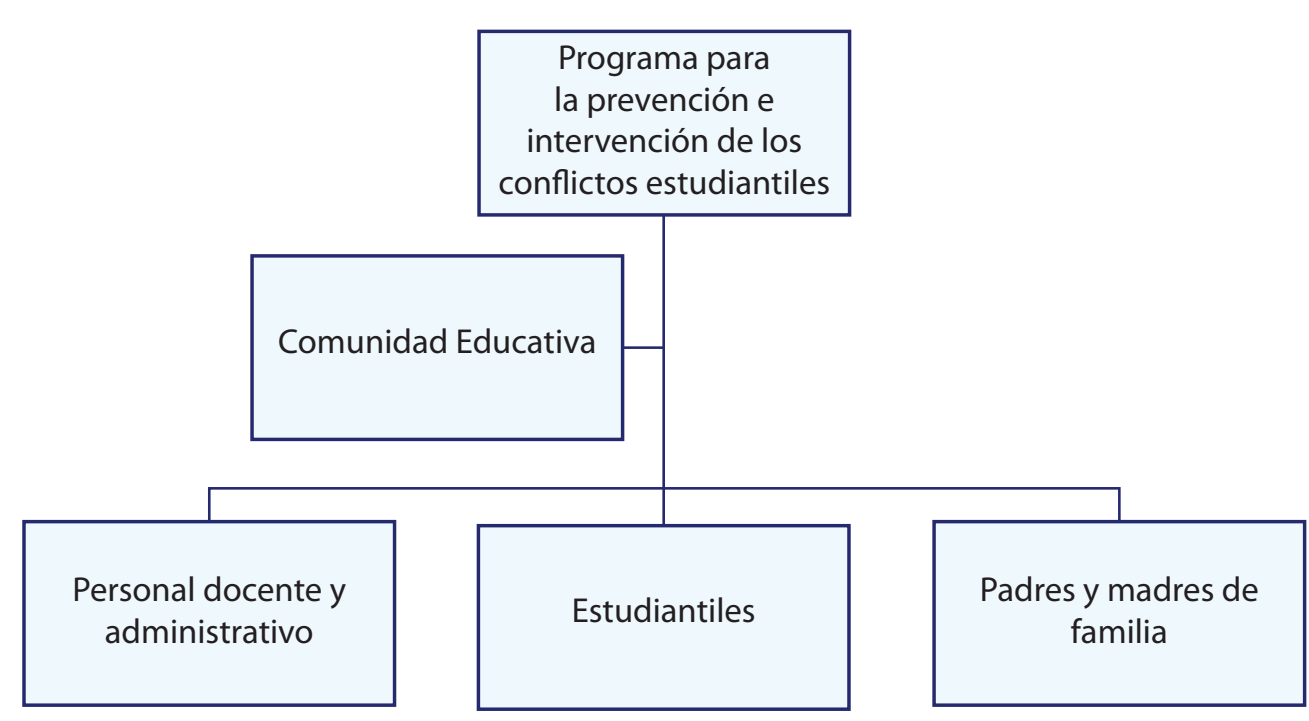

Figura 1. Esquema de la propuesta

Fuente: Elaboración del investigador.

El manual busca brindar soluciones alternativas, mediáticas y diversas, no definitivas. Estas necesitan ser abordadas de forma integral, a partir de diferentes y múltiples aspectos educativos. La gestión de los conflictos requiere de una serie de herramientas e instrumentos que colaboren con una solución pacífica de los mismos. Desde esta óptica, es el director quien debe ejercer un liderazgo en estos ámbitos. Este liderazgo no solo implica poseer o adquirir las habilidades sociales necesarias para ejercer su profesión con éxito y ser un buen negociador y mediador, sino también conocer diferentes estrategias que colaboren no solo con el tratamiento de los diferentes conflictos suceden en la institución, además de gestionar estrategias que colaboren en la prevención de estas situaciones, para así colaborar con la formación integral de los estudiantes y de la sociedad nacional. 


\section{Descripción del manual}

El marco referencial para el desarrollo de un manual para la gestión de los conflictos a partir del desarrollo de las habilidades sociales, se sustenta dentro de un marco conceptual amplio, por lo que abarca contenidos relacionados con la mediación escolar, la resolución pacífica de los conflictos, en los que se contemplan tres aspectos: la gestión administrativa, la gestión curricular y la gestión del recurso humano. Dentro de este marco referencial, se destacan las siguientes temáticas: la gestión del conflicto como algo inherente a las funciones administrativas de los profesionales en administración de la educación; entre estas habilidades destacan: la percepción de los conflictos; herramientas que estimulen la comunicación asertiva y el diálogo; estrategias para fomentar la resiliencia; la potenciación de los valores que colaboren con una cultura de paz; el desarrollo de habilidades de autorregulación y autocontrol y la práctica de actividades recreativas y deportivas, entre otras.

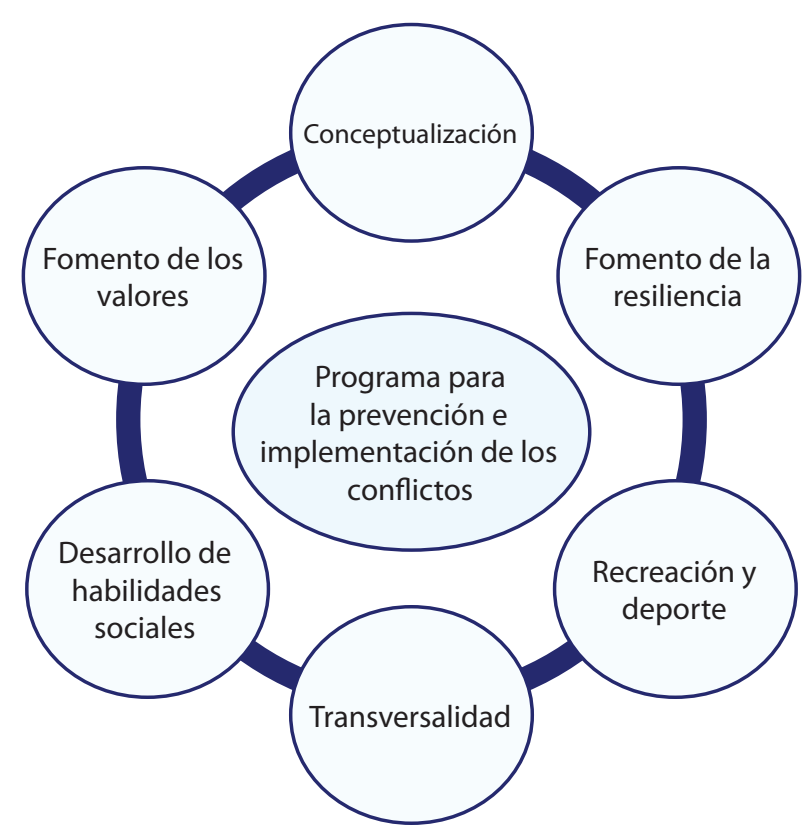

Figura 2. Gestión de los conflictos estudiantiles

Fuente: Elaboración del investigador.

Como se muestra en la figura 2, la gestión de los conflictos consiste en un proceso para la intervención y prevención de las diferentes situaciones relacionadas con los conflictos estudiantiles, a nivel organizacional. Este manual se constituye en una herramienta mediante la cual los profesionales en administración de la educación, por medio de diversas estrategias, 
puedan hacer frente a los diferentes conflictos que a diario suceden en la organización educativa, de una forma creativa y constructiva.

Una gestión exitosa de los conflictos realizada por parte de las autoridades institucionales, garantizará un clima de convivencia sano y la puesta en práctica de los principios democráticos que colaboren con una mejora de las relaciones interpersonales y por ende, en una reducción de la disrupción escolar y de los conflictos estudiantiles. La gestión de los conflictos consiste en un tratamiento pedagógico, cuya piedra angular se constituye en la mediación pedagógica y la instrumentalización de diversas estrategias que colaboren con una toma de conciencia y puesta en práctica de valores y principios fundamentales para el fomento de una sana convivencia y el beneficio mutuo, por medio de la búsqueda de estrategias mediáticas en las organizaciones educativas.

Gestionarconflictosdesdeestaperspectiva, significaquelosprofesionales enadministración de la educación se constituyen en líderes transformacionales de sus organizaciones, es decir, en agentes de cambio que impulsen en los mismos valores: la convivencia, la solidaridad, el respeto, la participación democrática, entre otros, componentes esenciales para la formación integral de los estudiantes; asimismo, contribuyen a incentivar un sentido de pertenencia y de compromiso por parte de todos los actores que conforman la organización.

El manual está integrado por ocho módulos, cada uno de ellos responde a diferentes habilidades sociales que se consideran fundamentales para un sano ejercicio de la gestión de los conflictos a nivel organizacional. Para cada uno de ellos, se brinda una descripción general y propósito de cada estrategia; así como actividades sugeridas, según sea lo que se pretende lograr y la población que se pretende capacitar.

Con base en estas consideraciones, se fundamenta el diseño del manual en cuanto a que una de las estrategias que a nivel administrativo de la educación se utiliza es la mediación; para esto, es imprescindible la utilización del diálogo y el consenso entre las partes. En torno a la intervención de los conflictos es importante que las autoridades tomen conciencia de lo fundamental que es para su abordaje, el trabajo en equipo y la solidaridad organizacionales; ante esto, es prioritario que se construya un programa integral de gestión de los conflictos. La dirección debe informar a toda la comunidad educativa sobre los diferentes procesos, proyectos y programas que se implementan a nivel institucional, incluyendo el reglamento de disciplina. De esta forma, se asegura que la información llega a sus destinatarios.

Para esto, es importante la búsqueda de otras alternativas correctivas, ya que para los estudiantes las boletas ya no cumplen con su función. Esto mismo debe inculcarse en los docentes, sobre todo hacia aquellos que se muestran indiferentes ante este tipo de situaciones; ante este fenómeno, los docentes deben tener claro sus funciones y deberes. 


\section{Estrategias de Mediación}

El método que se va a emplear se basa en tres momentos claves: ver, juzgar y actuar, como se muestra en la figura 3. Según Blasco (1993), este método es más dinámico y participativo:VER (dinámica a utilizar: observación de videos, análisis de canciones, foto, dinámicas, estudios de casos); JUZGAR pronunciamiento después de un análisis de las situaciones y conflictos); ACTUAR (conclusiones) y la evaluación. La razón fundamental de utilizar este método, "es enseñar a cada joven un sistema para aprender a resolver sus dificultades, sus dudas, su presente, su futuro, sus acciones, comprendiendo la necesidad de analizar la situación en la forma más objetiva posible para obtener una conclusión acertada" (Blasco, 1993, pp. 219-220).

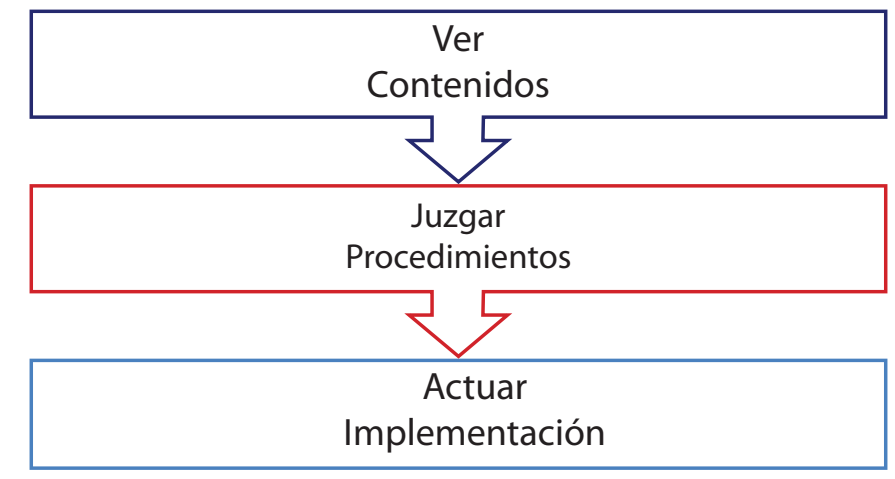

Figura 3. Metodología de la propuesta

Fuente: Elaboración del investigador.

\section{Las estrategias de mediación y sus momentos claves}

\section{Introducción}

Se trata de una explicación breve de lo que se va a hacer en cada sesión. Se realiza una especie de conversatorio relacionado con la temática; una inducción breve que puede ser acompañada de alguna reflexión, canción y video. Esto supone, partir de los intereses o ideas previas de los asistentes, para motivarles haciéndoles partícipes de los procesos de gestión y de las actividades de juego orientadas a la reflexión del tema por tratar.

Ver

Esta se constituye en una etapa descriptiva de la información y visión; equivale a un análisis de la realidad, a la captación de los acontecimientos, al examen de los signos de los tiempos, 
a la percepción de los hechos por medio de preguntas facilitadoras y otros medios para la comprensión de la temática. Según Iriarte citado por Floristán (1993), consiste en "observar los fenómenos, los mecanismos internos, las estructuras, las teorías que se hallan en juego" (p. 201); en este segmento, se brindan los temas por desarrollar; para esto, como un primer paso, se toman en cuenta los conocimientos previos e intereses que poseen cada uno de los participantes.

En esta parte, lo que se pretende es fomentar la construcción socializada del conocimiento y la motivación por parte de cada uno de los participantes, para que, de esta forma, tomen conciencia de la relación existente entre los temas por estudiar y su vida cotidiana. Para el logro de estos propósitos, es importante emplear estrategias como la lluvia de ideas, dinámicas grupales, videos y juegos, entre otros, lo que busca también involucrar y socializar a los participantes y al facilitador.

Juzgar

Esta parte es la fase interpretativa de iluminación y reflexión acerca de la problemática en estudio; relacionada con las preguntas facilitadoras, busca que los participantes se sientan protagonistas tanto en el análisis como en la búsqueda de alternativas; es el juicio crítico de los participantes, los cuales se sienten implicados en las problemáticas, por medio de sus aportes y opiniones con respecto de la gestión de los conflictos estudiantiles. En otras palabras, es el juicio crítico que se realiza por parte de los participantes; mediante este juicio se trata de ver la realidad en lo que a gestión de los conflictos estudiantiles se refiere.

En esta parte, se intenta que los principales protagonistas de las actividades sean los mismos participantes; para esto se organizarán actividades en las cuales ellos se impliquen, sobre todo en aquellas en las que experimentarán diferentes tipos de conflictos.

\section{Actuar}

Por medio de trabajos grupales y cooperativos, deben facilitarse actividades en las cuales los actores se involucren y participen activa y reflexivamente de éstas. Dicha participación se hace efectiva por medio de todas y cada una de las actividades propuestas.

Cada uno de los participantes deberá tomar conciencia de sus actuaciones (actitudes, valores), presentes y futuras, en relación con las diferentes situaciones analizadas. Es decir, al tomar conciencia del problema, pondrá en ejecución sus deberes y responsabilidades con la situación.

Se buscará favorecer, por medio de diversas actividades grupales y cooperativas, el trabajo en equipo, en cuanto a la búsqueda de soluciones y alternativas a los diversos problemas que se le presentan, en relación con la gestión de los conflictos estudiantiles. 


\section{Módulos de trabajo}

En las siguientes tablas, se presentan los diferentes módulos de trabajo que constituyen el manual, a partir de la metodología descrita anteriormente.

\section{Tabla 1}

\section{Módulo de trabajo l: Gestión de los conflictos.}

Objetivo: Indagar acerca del estado de la gestión de los conflictos en la organización, por medio de un diagnóstico institucional.

\section{Introducción}

Ver

Juzgar
Tema: Diagnóstico institucional y puesta en práctica de diversas estrategias para la prevención e información primaria.

El diagnóstico se constituye en un instrumento esencial para autodescubrir fortalezas, debilidades, oportunidades y amenazas en lo que a los conflictos y su tratamiento se refiere. Desde este punto de vista, el diagnóstico es, según Carbonell y Peña (2001, p. 138), "el punto de partida para realizar un proyecto de mejora de la convivencia en el contexto de la organización del centro educativo, es sin lugar a dudas, el diagnóstico del mismo en cuanto a los principales problemas y necesidades susceptibles de ser detectados a través de diversos métodos e instrumentos".

Diagnóstico institucional (matriz FODA); campañas de sensibilización e información; encuestas y cuestionarios para la población estudiantil; encuestas y cuestionarios para el personal docente; encuestas y cuestionarios para directores y administrativos; encuestas y cuestionarios para los padres de familia. Reuniones de trabajo con diferentes delegaciones de estudiantes (gobierno estudiantil, asamblea de representantes, juntas directivas, entre otros); reuniones de trabajo con el personal docente y administrativo; reuniones de trabajo con los padres y madres de familia.

Formación de diversos comités: Comité de gestión de los conflictos; Comité de mediación y Comité para la convivencia y la práctica de los valores.

Gestionar un manual para la convivencia, con la participación de todos los integrantes de la comunidad educativa. Trabajo curricular: introducir el tema transversal gestión de los conflictos.

¿Cómo elaborar un buen diagnóstico institucional que propicie las estrategias necesarias para la gestión de los conflictos? ¿Cómo estructurar campañas para la prevención de los conflictos? ¿Cuáles son los medios más eficaces en la promoción y la prevención de los conflictos? ¿Qué tipo de comités deben intuirse para el intervención de los diferentes tipos de conflictos que se presentan a nivel institucional? ¿Quiénes deben participar en la elaboración de un proyecto educativo para la gestión de los conflictos? Lectura y análisis crítico de los diferentes reglamentos que se relacionan, de forma directa o indirecta, con la disciplina de los estudiantes y sus derechos. 
Ejecutar el diagnóstico institucional, por medio del instrumento FODA y así tomar las medidas necesarias para facilitar el proceso para la gestión de los conflictos. Realizar diferentes campañas, a lo largo del año, en relación con la

Actuar prevención de los conflictos estudiantiles. Elaborar con base en el diagnóstico y la participación representativa de la comunidad educativa, un Proyecto Institucional para la gestión de los conflictos. Fomentar una cultura para la gestión de los conflictos.

Evaluar

El diagnóstico institucional y sus resultados

Proyectos de gestión corresponsable de los conflictos.

Fuente: Elaboración del investigador.

\section{Tabla 2}

\section{Módulo de trabajo Il: Estrategias para la gestión de los conflictos.}

Objetivo: Identificar los diferentes tipos de conflictos por medio de diferentes estrategias individuales y grupales.

Introducción

Ver
Tema: El conflicto y sus elementos

El conflicto se constituye en algo común de la vida de las personas, sobre todo cuando entre ellas surgen disparidades en las cuales los intereses se contraponen. En otras palabras, se suscita un conflicto cuando dos o más personas no pueden hacer compatibles sus objetivos.

Los conflictos son situaciones en las que dos o más personas entran en oposición o desacuerdo, porque sus posiciones, intereses, necesidades, deseos o valores son incompatibles, donde juegan un papel importante las emociones y sentimientos (Torrego, 2005, p.37).

Se debe tomar en cuenta que una de las principales estrategias para la gestión de los conflictos consiste en la formación de los alumnos como mediadores y gestores de alternativas pacíficas; de esta forma, son los mismos estudiantes quienes gestionan los conflictos a nivel interno de las organizaciones; "el alumno mediador gestiona los conflictos entre los alumnos, que por lo general se producen en el recreo" (Tartar, 2008, p.276).

El conflicto en la vida ordinaria de las personas.

Tipos de conflictos y sus diferentes manifestaciones.

Elementos característicos de los conflictos en relación con las personas.

Las emociones y los sentimientos, intereses y necesidades humanas.

Elementos relativos al proceso: la dinámica de los conflictos, la relación y la comunicación; estilos de enfrentamiento al conflicto; la comunicación. Gestión corresponsable de los conflictos.

Formación de alumnos mediadores. 


\begin{tabular}{ll}
\hline Juzgar & ¿Qué es el conflicto? ¿Cuáles tipos de conflictos existen? \\
¿Diferentes percepciones en relación a los conflictos? \\
¿Cuáles deben ser las actitudes básicas para la resolución de los conflictos? \\
¿Cuáles son las estrategias más efectivas, según sea la modalidad del \\
Conflicto? \\
¿Cómo enseñar a los jóvenes a gestionar sus propios conflictos \\
¿Cuál es la importancia que poseen las emociones, los valores, intereses y \\
sentimientos en la vida de las personas? \\
\hline Análisis del documento "Guía para el análisis del conflicto"; perfil de un \\
alumno mediador. \\
Formación del Comité de Planeación. \\
\hline \\
Valorar la importancia que tiene conocer y distinguir los diferentes tipos de \\
conflictos que se están en el contexto. \\
Determinar el proceso adecuado para realizar el procedimiento apropiado \\
en la gestión de los conflictos. \\
Valorar las ventajas que posee la mediación como un procedimiento de \\
gestión de los conflictos que colabora con el mejoramiento de la convi- \\
vencia escolar. \\
Competencia para una intervención de los conflictos institucionales. \\
\hline
\end{tabular}

Fuente: Elaboración del investigador.

\section{Tabla 3}

\section{Módulos de trabajo III: Estrategias para la gestión de los conflictos.}

Objetivo: Determinar la mediación como una herramienta eficaz para la gestión de los conflictos estudiantiles.

Introducción
Tema: La mediación

La mediación es una estrategia de negociación que permite la apertura de espacios para el diálogo y la gestión de los conflictos de una forma positiva. Para una eficaz aplicación, se necesita la intervención de un tercero al que se denomina como mediador, a quien le toca realizar el arbitraje y juicio. Según San Martín (2003) "la mediación escolar ayuda a la Comunidad Educativa a analizar y resolver los conflictos desde perspectivas participativas y positivas, atentas y respetuosas con los sentimientos e intereses de los otros" (p.99); entre sus principales propósitos están: promover la gestión positiva de los conflictos, pacificar las partes, crear un clima escolar pacífico y constructivo que colabore con la autoestima y afirmación personal, establecer y fomentar los lazos de confianza, fomentar una actitud positiva y optimista ante la vida (San Martín, 2003). 


\begin{tabular}{cl}
\hline Ver & $\begin{array}{l}\text { Distintas estrategias para la resolución de conflictos. La mediación como } \\
\text { una estrategia para la gestión de los conflictos. Las diferentes etapas de } \\
\text { la mediación, ventajas de la mediación. La mediación en la legislación } \\
\text { costarricense. }\end{array}$ \\
\hline Juzgar & $\begin{array}{l}\text { ¿Cuáles son las técnicas más frecuentes en la resolución de los conflictos? } \\
\text { ¿En qué consiste la mediación escolar y sus diferentes estrategias de inter- } \\
\text { vención? ¿Cuáles son las ventajas del establecimiento en la institución de } \\
\text { un manual de mediación escolar? ¿Cuáles son los procedimientos adecua- } \\
\text { dos para la gestión de los conflictos institucionales? }\end{array}$ \\
\hline Actuar & $\begin{array}{l}\text { Análisis del documento "Técnicas alternativas de resolución de conflictos". } \\
\text { Fases de la mediación escolar; ideas previas acerca de la mediación escolar. }\end{array}$ \\
\hline & $\begin{array}{l}\text { La estimación de seguir con los procedimientos apropiados para una ade- } \\
\text { cuada gestión de los conflictos. Valorar las ventajas que posee la mediación } \\
\text { como un procedimiento de gestión de los conflictos que colabora con el } \\
\text { mejoramiento de la convivencia escolar. Competencias para una interven- } \\
\text { ción eficiente de los conflictos institucionales. Reconocer las ventajas que } \\
\text { posee la mediación en la resolución de los conflictos. }\end{array}$ \\
\hline
\end{tabular}

Fuente: Elaboración del investigador.

Tabla 4

Módulos de trabajo IV: Habilidades sociales para la gestión de los conflictos.

Objetivo: Fomentar el trabajo cooperativo como una alternativa viable para la prevención de los conflictos estudiantiles.

Introducción
Tema: El trabajo en grupo (cooperativo).

Como parte del desarrollo de las habilidades asertivas, el trabajo en grupo es una habilidad esencial en lo que al logro de los objetivos se refiere. La cooperación busca aunar los esfuerzos del grupo dirigidos e invertidos hacia un mismo propósito, la optimización del rendimiento del grupo. De acuerdo con Burguetr (1999, p.163) "el trabajo en equipo es el espacio idóneo para potenciar estas particularidades, conocerlas, aceptarlas, y favorecer el papel de cada uno [...]". El trabajo en equipo no es algo sencillo, ni tampoco hay que esperar que suceda de la noche a la mañana; lograr un auténtico y eficiente trabajo en equipo requiere de tiempo y paciencia, sobre todo cuando se trata de trabajar con los docentes. Este proceso lo describe Tartar (2008, p. 257) de la siguiente forma: "hay un largo camino por recorrer para que los equipos (dirección, pedagógico, educativo, sanitario, orientación...) trabajen juntos en la complementariedad y el intercambio desarrollando estrategias de cooperación, aceptando las críticas constructivas de todos y gestionando positivamente los conflictos [...]". El trabajo en equipo y la cooperación no debe circunscribirse solamente al ámbito institucional, sino también al interinstitucional; es decir, debe trascender su espacio geográfico y trabajar en cooperación con otras organizaciones educativas. 


\begin{tabular}{ll}
\hline El trabajo en equipo y su importancia. \\
Estrategias para el fomento de una cultura de cooperación. \\
Valores que fomentan el trabajo en equipo. \\
Competencias para trabajar en equipo: atreverse a exponer sus puntos de \\
vista, tomar una posición, aceptar las críticas, flexibilidad mental, ser opti- \\
mista, mantener integridad y ser tolerante, evaluar consecuencias, antici- \\
par y capacidad de adaptación. Competencias relacionales: interesarse por \\
los demás, tener confianza, crear un clima organizacional sano, favorecer \\
el intercambio de ideas, respeto por las opiniones, respeto por las normas, \\
intercambio de ideas, ser solidarios, cuidarse mutuamente, generar una crí- \\
tica constructiva, entre otras. Habilidades que se poseen para el trabajo en \\
equipo, pensamientos, ideas, valores entre otros. Reglamento de disciplina, \\
normas de convivencia, redes de cooperación interinstitucionales. \\
\hline ¿Cuál es la importancia que posee el trabajo en equipo para el desarrollo \\
personal y social? ¿Cuáles valores deben fomentarse para el desarrollo \\
del trabajo en equipo? ¿Qué tipo de estrategias deben emplearse \\
para el fomento del trabajo en equipo? ¿Cuál es la importancia que \\
posee el trabajo en equipo en la gestión de los conflictos estudiantiles? \\
¿Promueve el reglamento de disciplina una cultura para la convivencia \\
pacífica? ¿Cómo desarrollar las competencias del trabajo en equipo en la \\
comunidad educativa? ¿Cómo desarrollar las competencias relacionales \\
en la comunidad educativa? ¿Cómo se encuentran los vínculos con otras \\
instituciones para establecer la cooperación mutua?
\end{tabular}

Fuente: Elaboración del investigador.

\section{Tabla 5}

Módulo de trabajo V: Habilidades sociales para una comunicación eficaz.

Objetivo: Fomentar la comunica- Tema: La comunicación asertiva.

ción asertiva como una alternativa

para la prevención e intervención

de los conflictos estudiantiles. 


\begin{tabular}{cl}
\hline & Poseer la habilidad asertiva es una competencia esencial para el desarrollo \\
de las personas, es la capacidad de autoafirmarse socialmente, dentro de \\
un espacio de relación con los otros; como lo determina Burguett (1999, \\
p.163) "las habilidades asertivas se caracterizan por toda una serie de con- \\
ductas socialmente hábiles: "aquellas que la persona emite en un contexto \\
interpersonal para expresar sus sentimientos, actitudes, deseos, opiniones \\
y derechos de forma directa, no violenta y sincera...". \\
\hline Introducción & La comunicación asertiva y su importancia para la gestión de los conflictos. \\
& El proceso de comunicación eficaz. \\
& La escucha activa. Herramientas para fomentar habilidades de la escucha \\
activa y la asertividad. Obstáculos para una comunicación eficiente.
\end{tabular}

Fuente: Elaboración del investigador.

\section{Tabla 6}

Módulo de trabajo VI: Fomento de la resiliencia.

\begin{tabular}{ll}
$\begin{array}{l}\text { Objetivo: Desarrollar } \\
\text { habilidades relacionadas con la } \\
\text { resiliencia como un medio para } \\
\text { la prevención e intervención de } \\
\text { los conflictos estudiantiles. }\end{array}$ & Tema: Adolescencia (cambios físicos, psicológicos y afectivos). \\
\hline & $\begin{array}{l}\text { Esta actividad busca la potenciación de las competencias resilientes presentes } \\
\text { tantos en el personal docente y administrativo como en los estudiantes, por } \\
\text { medio del conocimiento de símismo y la comprensión de los diferentes cambios } \\
\text { físicos, psicológicos y afectivos de los adolescentes y las personas, en general. } \\
\text { Busca promover los potenciales resilientes en los adolescentes que pertenecen } \\
\text { a la organización educativa. } \\
\text { Adquirir un mejor conocimiento de símismo (introspección) y de los otros. } \\
\text { Elaborar un diagnóstico de la población escolar. Indagar factores protectores y de riesgo. }\end{array}$
\end{tabular}




\begin{tabular}{ll}
\hline Ver & Importancia de la resiliencia en la vida de las personas. \\
La adolescencia y sus diferentes etapas. \\
Características de la resiliencia como habilidad social. \\
\hline ¿La realidad de la etapa de la vida en la cual me encuentro ya sea como \\
adolescente o como adulto? ¿Mis actitudes ante la vida, ante el estudio, \\
ante la realidad que me circunda? ¿Cuál es la importancia de conocerse a sí \\
mismo? ¿Cuáles son mis fortalezas y debilidades de mi vida? ¿Cuáles son mis \\
valores? ¿Cuáles son los factores protectores y de riesgo que influyen positiva o \\
negativamente en las actitudes de las personas? \\
Visualizar el Film "Dead in América", por medio de un cine foro, se corroborarán \\
todos y cada uno de los factores protectores y de riesgo. Al mismo tiempo, \\
identificaran la importancia de potenciar la resiliencia en la vida de las personas. \\
\hline Juzgar & Según los instrumentos y las dinámicas propuestas, determinar las áreas \\
fuertes y débiles por medio de la matriz FODA (fortalezas, oportunidades, \\
debilidades y amenazas). Se trabajan las debilidades con las oportunidades \\
y las fortalezas con las amenazas, para hacer un cruce de información y \\
realizar las conclusiones pertinentes. \\
\hline De acuerdo con la aplicación de las técnicas propuestas, se evalúan los \\
siguientes aspectos: Analizar el grado de conocimiento con respecto del \\
tema de la resiliencia y su importancia para la vida. \\
Determinar el grado de conocimiento con respecto a los factores \\
protectores y de riesgo presentes durante su etapa de adolescentes, de \\
tal forma que los estudiantes identifiquen en sus vidas estos factores para \\
determinar áreas fuertes y débiles para trabajar en ellas. \\
El impacto que tuvo el uso de las técnicas en los estudiantes, sobre todo en \\
las propuestas de cambio que de ellos mismos deben generarse. \\
\hline
\end{tabular}

Fuente: Elaboración del investigador.

Tabla 7

Módulo de trabajo VII: Fomento de la resiliencia

\section{Objetivo: Desarrollar} habilidades relacionadas con la resiliencia como un medio para la prevención e intervención de los conflictos estudiantiles.
Tema: Familia y adolescencia. 


\begin{tabular}{|c|c|}
\hline Introducción & $\begin{array}{l}\text { La familia es el primer núcleo de socialización para las personas y en especial, } \\
\text { para los niños y jóvenes. Es en el seno de la familia donde los adolescentes y niños } \\
\text { deben afianzar sus procesos de socialización, tanto en lo que compete al seno } \\
\text { familiar como al resto de sus relaciones interpersonales. Desde esta perspectiva, la } \\
\text { familia podría jugar un doble rol, según sea el contexto en el cual ésta se genere, } \\
\text { por una aparte podría convertirse en un factor protector si ella es, en sí misma, } \\
\text { una estructura funcional que permite el desarrollo integral de cada uno de sus } \\
\text { miembros y por otra parte, en una factor de riesgo en tanto la disfuncionalidad es } \\
\text { tal que no permite este desarrollo armónico de las facultades y de las habilidades } \\
\text { sociales necesarias de cada uno de sus integrantes. Así lo expresa Carbonell y Peña } \\
\text { (2001, pp. 52-54) "se reconoce que la expresión de la conducta agresiva infantil y, } \\
\text { también, el concepto que el niño tenga de sí mismo, en relación con su estima per- } \\
\text { sonal, dependerá esencialmente de las características propias de la personalidad } \\
\text { paterna... una de las funciones fundamentales de la familia es la de socialización } \\
\text { de los hijos, pero no siempre es un medio "sano", antes al contrario puede llegar a } \\
\text { convertirse[...] en un medio patógeno de socialización". } \\
\text { Fomentar la resiliencia en la familia se constituye en un factor protector } \\
\text { para los jóvenes, sobre todo para que tomen conciencia de las ventajas y } \\
\text { desventajas que el contexto familiar le ofrece. }\end{array}$ \\
\hline Ver & $\begin{array}{l}\text { El contexto familiar y sus características. } \\
\text { Diferentes modelos de familias. } \\
\text { Rol del adolescente en la familia y viceversa. } \\
\text { Factores protectores y de riesgo de la familia actual. }\end{array}$ \\
\hline Juzgar & $\begin{array}{l}\text { ¿Cuáles son los tipos de familias que hay? ¿Cuál es el lugar que ocupa el } \\
\text { adolescente dentro de la familia y el lugar que ella ocupa para él o ella? ¿Es } \\
\text { la familia un factor de protección o de riesgo? ¿Cuáles deben ser las normas } \\
\text { y valores que la familia debe trasmitir? }\end{array}$ \\
\hline Actuar & $\begin{array}{l}\text { Por medio de la película "Dead in América", identificar los diferentes tipos } \\
\text { de familia en los cuales se desenvuelven los jóvenes y los diferentes roles } \\
\text { que juegan los adolescentes en ellas. } \\
\text { ¿Cuáles fueron los factores protectores y de riesgo de cada una de las } \\
\text { familias que aparecen en el film? }\end{array}$ \\
\hline Evaluar & $\begin{array}{l}\text { De acuerdo con la aplicación de la técnicas propuestas, se evalúan los } \\
\text { siguientes aspectos: } \\
\text { Analizar el grado de conocimiento con respecto al tema de la resiliencia y } \\
\text { su importancia para la vida. } \\
\text { Determinar el grado de conocimiento con respecto a los factores protec- } \\
\text { tores y de riesgo presentes durante su etapa de adolescentes, de tal forma } \\
\text { que los estudiantes identifiquen en sus vidas estos factores para determi- } \\
\text { nar sus áreas fuertes y débiles para trabajar en ellas. } \\
\text { El impacto que tuvo el uso de las técnicas en los estudiantes, sobre todo en } \\
\text { las propuestas de cambio que de ellos mismos deben generarse. }\end{array}$ \\
\hline
\end{tabular}

Fuente: Elaboración del investigador. 


\section{Tabla 8}

\section{Módulo de trabajo VIII: Gestión en la prevención de los conflictos.}

Objetivo: Identificar los factores
protectores y de riesgo relaciona-
dos con los conflictos estudiantiles.

Introducción

Ver

Juzgar

Actuar

Evaluar
Tema: Factores protectores y de riesgo.

El conocimiento preventivo de los factores de riesgo y el fomento de los factores protectores son aspectos medulares en que a la gestión de los conflictos se refiere. Según el Subprograma Derechos del Niño y del Adolescente del Ministerio de Educación, Ciencia y Tecnología de Argentina (s.f.) "se entiende por factor de riesgo a cualquier característica o cualidad de una persona, comunidad o del entorno, que se sabe va unida a una elevada probabilidad de dañar la salud. En virtud de este esquema solemos pensar que, si una persona está expuesta a varios factores de riesgo, es muy probable que enferme [...]". Los factores protectores son los aspectos del entorno o competencias de las personas que favorecen el desarrollo integral de individuos o grupos y pueden, en muchos casos, ayudar a transitar circunstancias desfavorables.

Factores protectores y su influencia en la prevención de los conflictos: creación de redes de contención (padres o familiares cercanos; instituciones que colaboran con la prevención del maltrato, ya sea a nivel psicológico o judicial). Por otra parte, acciones que promueven la autoestima, la confianza en sí mismo y el reconocimiento al que se tiene derecho de ser querido. Redes de apoyo con adultos, docentes y equipos interdisciplinarios. Factores de riesgo y su incidencia en los conflictos: el aislamiento con respecto a las redes sociales defensoras, la indiferencia o la negación del problema que padece, ver como algo natural los conflictos y la violencia que suceden a nivel local y nacional; la reproducción de los hechos conflictivos y violentos, familias disfuncionales, padres violentos, conflictos entre docentes y estudiantes, la pobreza, el flagelo de las drogas, entre otras.

¿Cómo influyen los factores protectores en el desarrollo de competencias para la gestión de los conflictos? ¿Cuál es la incidencia de los factores de riesgo en el apogeo de los conflictos entre las personas? ¿Cómo generar espacios a nivel institucional para el análisis y la reflexión de los diversos factores?

Identificar, por medio de un cuestionario, los factores protectores y de riesgo presentes en el Film "Dead in América", para tomar una posición vital al respecto.

Análisis de los documentos "Lo bueno que yo tengo" y "A quién le tienes confianza". 
Tabla 9

\section{Módulos de trabajo IX: Desarrollo de habilidades sociales.}

Objetivo: Desarrollo de las habilidades sociales para el desarrollo integral de las personas.
Tema: Autoestima, afirmación y confianza.

Identificar qué áreas de la autoestima están altas y cuáles están bajas.

Determinar la autoestima, la afirmación y la confianza como factores esenciales para el desarrollo integral de la persona.

El desarrollo de habilidades sociales relacionadas con la autoestima, la afirmación y la confianza son fundamentales para el desarrollo personal, sobre todo en lo que compete a la resolución de los conflictos. Estos tres aspectos son vitales para el crecimiento y desarrollo integral de la persona, sirven como guía al comportamiento y las actitudes de las personas, tal como se menciona "la autoestima, afirmación, confianza[...] conforman aspectos críticos para el desarrollo personal y por lo tanto, influyen en la resolución de conflictos" (Salm, 2006, p.93).

La autoestima es el valor que una persona tiene por sí misma, es el autoconcepto; es decir, es la manera en la que ella se percibe y se describe a sí misma; "para la resolución de conflictos, la buena autoestima es importante...es tan importante en las causas de los conflictos como en su resolución" (Salm, 2006, p.95).

La afirmación se constituye en "una acción que valida una persona o una acción de esta- es cualquier comentario o nota que muestra que la persona en conjunto o que una acción estuvo bien hecha- normalmente recibimos afirmaciones o elogios, que nos hacen sentir bien u orgullosos. Pero, unas personas no las reciben, y nunca saben si hacen cosas buenas o si son personas buenas" (Salm, 2006, p.96).

La confianza es un tema de suma trascendencia en la resolución de los conflictos. Poseer confianza cuando se enfrentan situaciones conflictivas es vital para su resolución, sobre todo tener confianza en los otros, en que el proceso va a suceder y tener fe que todo va a salir bien. La confianza se gana por medio de las acciones y la responsabilidad.

Importancia del desarrollo de la autoestima, la afirmación y la confianza en la configuración de la personalidad.

Importancia de la autoestima, la afirmación y la confianza en la resolución de los conflictos.

Factores que no contribuyen a un sano desarrollo de la autoestima, la afirmación y la confianza.

¿Cuáles son los factores que contribuyen al sano desarrollo de la autoestima, la afirmación y la confianza?

¿Cuáles son los factores no contribuyen al sano desarrollo de la autoestima, la afirmación y la confianza?

Estrategias y procesos para el sano desarrollo de estas habilidades 


\begin{tabular}{ll}
\hline Realización de diversas actividades que promuevan la toma de conciencia y \\
el desarrollo de la autoestima desde una perspectiva integral, partiendo de \\
las siguientes preguntas generadoras: ¿Cómo me siento yo con mi autoes- \\
tima? ¿Qué factores han influido en mi vida de forma positiva para el desa- \\
rrollo de mi autoestima? ¿Cuáles de forma negativa? ¿Que estoy haciendo \\
en relación con mi autoestima? ¿Cómo influye la autoestima en el desarrollo \\
y en resolución de los conflictos a nivel personal?
\end{tabular}

Fuente: Elaboración del investigador.

\section{Estrategias para la mediación para los módulos de gestión de los conflictos estudiantiles}

Este apartado contiene algunas dinámicas y actividades intencionalmente colocadas, para el desarrollo de cada uno de los módulos de la propuesta. Esto no significa que sean las únicas para la implementación del mismo.

\section{Modulo I Gestión de los conflictos}

Formación del Comité de Convivencia

Pasos por seguir

1- Conformación de una comisión para el planeamiento y gestión de los conflictos estudiantiles.

2- Diagnóstico de la realidad conflictiva organizacional.

3- Planeación del manual de Gestión de los conflictos.

4- Implementación del Plan de Acción.

5- Redefinición de los objetivos, las metas y estrategias.

6- Implementación institucional.

\section{Conformación de una comisión para el planeamiento y gestión de los conflictos estudiantiles}

El papel del comité para la gestión de los conflictos estudiantiles o de convivencia, es primordial. Este comité será el encargado de facilitar, implementar y evaluar todas y cada de las estrategias propuestas en los módulos; estará integrado por un representante del Departamento de Orientación, el psicólogo institucional, el o los encargados de disciplina, representantes del sector estudiantil y del sector de padres de familia. Entre las funciones que debe tener este comité están: establecer las metas, los participantes, la metodología, la pedagogía, tiempo, cronograma, entre otros. 


\section{Metas}

Una gestión eficaz de los conflictos que comprenda: un manual para la prevención e intervención efectiva de los conflictos, por medio del fomento de las habilidades sociales; la continuidad y actualización del manual; la construcción de habilidades en los estudiantes para la resolución de los conflictos y problemas; fomento de valores y actitudes que equivalentes a las buenas relaciones; fomento de todos aquellos valores que colaboren con el fomento de una cultura de paz dentro de la organización.

\section{Estrategias didácticas}

Conceptos relativos a los conflictos estudiantiles; gestión de los conflictos estudiantiles; tipos de conflictos; métodos para la prevención; habilidades sociales; actitudes y valores.

\section{Módulo: Gestión de los conflictos. Inducción a los talleres para la gestión de los conflictos} estudiantiles.

Objetivos:

- Determinar los contenidos y los objetivos del manual.

- Propiciar un clima agradable entre los participantes, por medio de actividades grupales que fomenten el trabajo en equipo.

- Brindar un espacio para que los participantes expresen sus inquietudes con respecto del proceso de gestión.

Se utiliza la dinámica de presentación "El ovillo de lana" para propiciar un conocimiento básico de la vida y características de todos los colaboradores.

Los participantes, en subgrupos de 5 a 10 personas, forman un círculo. Uno de ellos posee un ovillo de lana y lo lanza al otro compañero que está al frente. Momentos antes de lanzarlo, en voz alta dice: "me llamo........." y "quiero poner al servicio de ustedes.........." (Menciona una cualidad personal positiva). Cuando termina, sin soltar el hilo, se lo lanza a otra persona, de tal forma que el mismo quede tenso (no puede tocar el suelo); así sucesivamente, hasta que todos tengan una punta del hilo y formen una especie de estrella. La dinámica debe hacerse de forma ágil, lo que implica que cada uno de los integrantes realice una introspección rápida con respecto a sus cualidades y valores. Si alguien se bloquea, debe lanzar el ovillo a otra persona.

Es importante que al terminar la actividad, cada uno de los integrantes expresen libremente: ¿Cómo se sintieron con la actividad? ¿Les resultó dificultoso decir una cualidad? ¿Cuáles son sus potencialidades y habilidades sociales? ¿De qué forma esas cualidades van a servir dentro de los procesos de gestión de los conflictos? En relación con la estrella, ¿Cuál es 
su significado? ¿Qué pasó cuando socaba o aflojaba el hilo? ¿Cuál es la relación que ésta posee con el trabajo en equipo? ¿Se presentó algún tipo de conflictos? ¿Cuáles? ¿Qué hicieron para resolverlos?

\section{Módulo: Gestión de los conflictos}

Presentación Manual de gestión de los conflictos estudiantiles.

Objetivos:

- Identificar las expectativas de los asistentes.

- Determinar los conocimientos que los participantes poseen con respecto del manual.

Con el fin de conocer las expectativas de los participantes, se realiza la dinámica "los dos carteles", en los cuales se presentan los encabezados de "lo que si quiero que ocurra" y "lo que no quiero que ocurra".

Los participantes escriben en el papel sus opiniones en relación con la metodología, contenidos, grupo, manual; los pegan en los carteles correspondientes. Pasado un tiempo prudente, se hace una lectura en voz alta de lo escrito en cada uno de los papelitos, hay que permitir que todos expresen sus sentimientos al respecto. Esta actividad debe conectarse con la siguiente: "el contrato". Al final, se guardan los papeles para contrastarlos con la evaluación final.

Es importante que al terminar la actividad, cada uno de los integrantes expresen libremente: ¿Socalzar las diversas expectativas y los diversos aportes que se tienen con respecto del manual?

Otra dinámica que se puede realizar, es la llamada "la mano", la cual pretende indagar las expectativas que poseen los participantes en relación con los contenidos a tratar.

Cada participante dibuja en una hoja la silueta de su mano, con los dedos extendidos y dentro de cada dedo escribe lo siguiente: En el meñique: su nombre; en el anular: motivo (s) por los que se están en el taller de gestión; en el corazón: algunas cosas que le gustaría sucedieran en las actividades; en el índice: cosas que no les gustarían que pasaran en el manual; en el pulgar: algo que quisiera adoptar en su vida al terminar el taller.

Cuando todos terminan sus opiniones en cada una de las manos, las pegan en el papel que está pegado en la pared. Posteriormente, se hace una lectura en voz alta; se conservan los papeles grafos hasta el final de la actividad.

Una tercera actividad es "el contrato", en la que hay que tener en cuenta la dinámica anterior; deben aclararse las prioridades de las necesidades, en el sentido del grado de satisfacción que 
pueden esperar. Se explica: ¿Cómo va a ser la estructura del manual? ¿Qué están dispuestos a hacer? ¿A qué se van a comprometer? A nivel de trabajo personal y de equipo.

\section{Modulo Gestión de los conflictos}

El conflicto y sus componentes

Objetivos:

- Conocer el papel quejuegan los conflictos en la vida y sus diversos componentes.

- Determinar estrategias efectivas para una gestión eficaz de los conflictos

Actividades

- Análisis de un conflicto.

1. El facilitador propone a los (as) participantes realizar un trabajo en pareja con la siguiente frase: "Cuéntele a tu compañero (a) algún conflicto que le haya afectado, y luego pide a tu compañero que te cuente otro a ti".

2. Seguidamente cada uno de los participantes que contesten a varias cuestiones relacionadas con los conflictos comentados, utilizando el Documento No 1 "Guía para el análisis de un conflicto"

3. Realización en puesta en común de cada una de las parejas de la actividad anterior.

Mediante la actividad "Guía para el análisis de un conflicto", se les solicita a los participantes que realicen una reflexión en relación con los conflictos descritos, anteriormente, para contestar a preguntas como: ¿Quiénes son los protagonistas? ¿Qué influencia ejercen las terceras personas? ¿Qué relación tiene A con B y viceversa? ¿Cómo se siente? ¿Cuánto tiempo lleva el conflicto? ¿El conflicto está polarizado, enquistado, relajado, latente, otros? ¿Cuáles son sus valores? ¿Qué les interesa resolver? ¿Qué posición tienen, qué demandan? ¿Qué propone para resolverlo?

Para llevar a cabo el análisis de cada uno de los componentes de los conflictos, el facilitador propone a los participantes, realizar una exposición creativa con respecto a cada uno de los elementos que constituyen los conflictos. Para el logro de estos fines, el facilitador brinda la información concerniente a cada uno de los elementos, de acuerdo con el siguiente esquema conceptual:

Elementos relativos a las personas (protagonistas, el poder en el conflicto, las percepciones del problema, las emociones y los sentimientos, las posiciones, intereses y necesidades, los valores y principios). 
Elementos relativos a la gestión (la dinámica del conflicto, la relación y la comunicación, estilos de enfrentamiento al conflicto, estilo de gestión de los conflictos, normas y reglamentos, estilos de comunicación).

Elementos relativos al problema (el asunto, tipos de conflicto).

Cada subgrupo habiéndose leído el documento dado por el facilitador procederá a realizar una exposición creativa en relación con el tema investigado. Esta exposición debe estar mediada por algún tipo de dinámica, estudio de casos o socio- drama.

\section{Modulo Gestión de los conflictos \\ La Mediación de los conflictos}

Objetivos:

- $\quad$ Distinguir diferentes modalidades para la gestión de los conflictos.

- Determinar la mediación como un estrategia eficaz para la resolución de los conflictos.

Con el objetivo de determinar la mediación como estrategia para la gestión de los conflictos institucionales, se realiza la dinámica "Mediación como estrategia para la gestión de los conflictos", utilizando estudios de caso para el análisis de situaciones conflictivas.

El facilitador presenta la dinámica a seguir con respecto a la temática; por medio de preguntas generadoras, induce a los participantes a opinar con respecto al conocimiento que poseen, la mediación de los conflictos y sus diferentes técnicas: arbitraje o juicio, diferentes alternativas formales y no formales para la resolución de los conflictos. Utilizando las opiniones de los participantes, el facilitador aclara conceptos e indaga acerca de las expectativas de los participantes.

Es importante que, al terminar la actividad, cada uno de los integrantes conozcan y practiquen técnicas para la mediación de los conflictos como una estrategia idónea para la gestión de los mismos, con la realización de la actividad denominada "La mediación como estrategia para la gestión de los conflictos".

Otra actividad es la dinámica "La mediación como estrategia para la gestión de los conflictos", la cual busca que los participantes respondan a las siguientes preguntas, primeramente de forma individual y seguidamente de forma grupal. Cada participante debe conformar, junto con los otros compañeros subgrupos de cinco personas, para ir resolviendo cada uno de los acertijos. 
1. ¿Cuál es el papel que juega el director, los docentes y estudiantes en los procesos de mediación y resolución de los conflictos?

2. ¿Qué es para usted la mediación?

3. ¿Cuál es la diferencia entre un árbitro, un mediador y un pacificador?

4. ¿Cuáles son las ventajas y desventajas que posee para ustedes que a nivel institucional en relación con que a nivel institucional se realice un manual para la gestión de los conflictos.

Adicionalmente, se pueden realizar estudios de caso y sociodramas, mediante los cuales cada uno de los grupos realiza una investigación corta para una mejor comprensión de la gestión de los conflictos, siguiendo el siguiente guión:

- ¿Qué te ha parecido la actuación de los mediadores? ¿Qué te pareció bien? ¿Qué aspectos no te parecieron agradables? ¿Qué opinas con respecto de la mediación?

- ¿Los mediadores colaboran con los procesos de gestión ya sea a nivel colegial y universitario? ¿Ayudaron a aclarar el problema? ¿Cómo?

- Los mediadores ¿facilitaron el consenso, la buena comunicación? ¿Se facilitó la creación de soluciones creativas?

- ¿Cuál es tu opinión con respecto de lo estudiado? ¿Qué crees debe cambiarse? ¿Cómo te has sentido?

- ¿Qué intervenciones te ayudaron a clarificar tus intereses? Y ¿tus sentimientos? ¿Cuáles ayudaron a resolver tus problemas? ¿Cuáles no?

\section{Modulo Gestión de los conflictos}

Diagnóstico institucional

Objetivos:

- Determinar las fortalezas y debilidades de la organización.

- Determinar las habilidades sociales necesarias para la prevención e intervención de los conflictos estudiantiles.

- Mostrar a los estudiantes sus respuestas más comunes frente a un conflicto.

Para el desarrollo del diagnóstico institucional se contemplan rubros como datos generales 
de la organización educativa, datos relacionados con la disciplina, la convivencia y los conflictos, otras interrogantes para el estudiantado y docentes.

Datos generales de la organización educativa:

- Nombre de la organización...

- Modalidad educativa...

- Dirección y número de tel.

- Nombre del director...

- Total de estudiantes

- Total de docentes

- Año fundación de la Organización

- Número de Comités existentes...

Datos relacionados con la disciplina, la convivencia y los conflictos:

- Cantidad de peleas físicas entre los estudiantes

- Cantidad de estudiantes involucrados en estas peleas

- Cantidad de expulsiones

- Cantidad de deserciones

- Ausentismo

- Armas e instrumentos de tipo bélicos encontrados.

Cuestionario para los estudiantes y docentes:

- ¿ ¿Ofrece la institución una participación equitativa en la toma de decisiones? ¿Se excluye a algunos estudiantes?

- ¿Existen problemas en la comunicación por parte de las direcciones y los docentes? ¿Cómo afecta esto a los estudiantes?

- ¿Consideran los estudiantes que a nivel interno de la institución ocurren muchos conflictos? ¿De qué tipo?

- ¿Existen muchos castigos en la institución? ¿De qué tipo?

- ¿Qué es lo que ocasiona más problemas en el Liceo?

- ¿Cuáles son las estrategias más comunes para la resolución de los conflictos? ¿Cuáles son las actitudes de los estudiantes en relación con los conflictos estudiantiles?

- ¿Cuál es la opinión que poseen los estudiantes con respecto del reglamento de disciplina que se aplica en la organización educativa? 
- ¿Qué opinan los estudiantes de los comportamientos de sus compañeros?

- ¿Cómo gestiona los conflictos la dirección? ¿De forma autoritaria? ¿De forma participativa? ¿Existen actividades que colaboren con la prevención e intervención de los conflictos estudiantiles?

- ¿Cuáles son los conflictos que más daño causan a la institución y su imagen?

- ¿Cómo son las actitudes de los estudiantes?

Como complemento de la estrategia es necesario desarrollar una actividad relacionada con la respuesta de cada participante a los conflictos, donde se especifique la conducta que manifiestan en las situaciones que se presentan. Entre los rubros a consultar están: si se busca ayuda, si se golpea a las personas, si se dialoga, si se muestra indiferencia, si se muestra tolerancia, presencia de chismes, ofrecimiento de disculpas, otros.

\section{Modulo Desarrollo de las Habilidades Sociales \\ Desarrollo de la autoestima \\ Adaptación del investigador de Salm (2006)}

Objetivos:

- Definir el significado de la autoestima

- Determinar las áreas altas y bajas de la autoestima.

- Fomentar la colaboración mutua en el fomento de la autoestima.

Con esta actividad se pretende definir el significado de la autoestima; elaborar una encuesta en relación con la autoestima; escribir las siguientes frases en la pizarra, con el fin de que los estudiantes indiquen la validez de las mismas en las situaciones de conflicto en que participan:

Poder personal:

- Comienzo todos los proyectos por mi cuenta, aun con dificultades de por medio.

- Cuando cometo un error trato de corregirlo

- Manejo bien el estrés y la presión.

- Soy capaz de comunicar mis sentimientos y necesidades

- Tomo decisiones con facilidad

- Resuelvo problemas sin dificultad 
Unicidad:

- Me gusta como soy

- Me gusta mi cuerpo

- Me gusta quien soy

- Usualmente soy cordial con los demás

- Cuando algo bueno me pasa, siento que lo merezco.

Modelos:

- Sé distinguir lo que es importante para mí.

- Existen personas en mi vida que estimo y respeto.

- Sé actuar con responsabilidad

- Poseo metas personales e intento alcanzarlas

- Sé con quién hablar cuando tengo problemas.

\section{Relaciones interpersonales:}

- Tengo amigos

- Mellevo bien con los otros.

- Me ayudan otras personas cuando lo necesito

- Me gusta trabajar en grupo

- Me siento cercano a mi familia

Cuando han terminado, los estudiantes deben contar las respuestas negativas en cada categoría y colocar el resultado en el espacio que se encuentra junto al título de cada sección. Luego se agrupan en parejas y discuten sus respuestas.

Se realiza una discusión relacionada con las áreas débiles y fuertes de cada uno de los integrantes, a partir de las siguientes preguntas: ¿Están sorprendidos por las respuestas? ¿Cómo pensaron que estaba realmente la autoestima de ustedes? ¿Cuál de las áreas te salió más alta? ¿Por qué? ¿Cómo te afecta la autoestima tus relaciones con las demás personas?

\section{A modo de conclusión}

Establecer estrategias para la gestión de conflictos estudiantiles permite al profesional en administración de la educación y personal docente de las organizaciones educativas, la debida 
atención, solución y hasta prevención de las situaciones problemáticas que se presentan entre el estudiantado, por medio de herramientas de mediación que concienticen a las partes involucradas hacia una convivencia pacífica, lo que fortalece el desarrollo de habilidades sociales en la población estudiantil.

\section{Referencias bibliográficas}

Blasco, M. (1998). Reconstrucción de persona. (Proyecto Pedagógico Amigoniano). Villa Alemana, Chile: CEA.

Burguet, M. (1999). El educador como gestor de conflictos. Bilbao, España: Desclée De Brouwer

Carbonell, J y Peña, A. (2001). El despertar de la violencia en las aulas. La convivencia en los centros educativos. Madrid: CCS

Chacón, A. (2011). La gestión de los conflictos estudiantiles: un enfoque desde la administración de la educación. Revista Gestión de la Educación, 2 (1), ISSN 2215-2288. Recuperado en: http://revistas.ucr.ac.cr/index.php/gestedu/article/view/8510

Chiavenato, I. (2006). Administración de recursos humanos. México D.F.: McGraw-Hill.

Delors, J. (1996). La educación encierra un tesoro. Madrid, España: Santillana

Fernández, I (2008). Prevención de la violencia y resolución de conflictos. Madrid, España: Narcea

Floristán, E. (1993). Doctrina social. Madrid: Paulinas.

Gómez, C. (2001). La juventud hoy. Recuperado en: http://www.aciprensa.com/Familia/ juventudhoy.htm

González, C (2009). Retos de la Administración Educativa. Recuperado en: www. congresoretosyexpectativas.udg.mx/Congreso

Ministerio de Educación, Ciencia y Tecnología de Argentina. (s.f.). Factores protectores y Factores de Riesgo: otro modo de pensar el destino de un niño. Recuperado en: http://derechos.educ. ar/docente/prevencion/factoresprotectores.htm 
Salm, R. (2006). La solución de conflictos en la escuela. Lima, Perú: Alfa y Omega.

San Martín, J. (2003). La mediación escolar: un camino para la gestión del conflicto escolar. Madrid: CCS.

Suárez, N. (1998).Manual de resiliencia en la niñez y la adolescencia -OPS-OMS. (Seminario: Resiliencia en niños (as), adolescentes y comunidades). San José, Costa Rica: Fundación Paniamor.

Tartar, E. (2008). Prevenir y tratar la violencia en la escuela. Bilbao, España: Mensajero.

Tierno, B. (1994). Valores humanos. Recuperado en: http://www.ahire.es/wp-content/uploads/ downloads/2011/05/Bernab\%C3\%A9-Tierno.-Valores-humanos.pdf

Torrego, J. (2005). Mediación de conflictos en instituciones educativas. Madrid, España: Narcea. 